\title{
Pollination with irradiated pollen in rice-Oryza sativa L. II. The second (M2) generation
}

\author{
Shin-Foong Chin* and \\ Geoff H. Gordon
}

Department of Agriculture, University of Queensland, St. Lucia, Queensland 4067, Australia.

Surviving M1 plants derived from pollination with irradiated pollen were selfed to produce the second (M2) generation. in three quantitative traits, the means and phenotypic frequency distributions of the M2 populations were identical to that of the F2 population. In five major gene traits, all but six of the $244 \mathrm{M} 2$ segregations were in the expected ratios is the F2's. Aberrant segregations produced both excess paternal as well as maternal phenotypes. There was no consistent trend of a "maternal shift" in the M2 generation that may render the technique of irradiated pollination useful by preferentially producing pure breeding maternal materials having a few specific paternal characteristics. overall, pollination with irradiated pollen in rice produced mainly normal hybrid progeny with very little heritable variations. These lack of responses in rice may be explained by the fact that rice pollen is relatively insensitive to irradiation on the one hand, and that the pollen genome is less able to accommodate mutational damage on the other hand. Thus, the rice plant is considered less amenable to the application of irradiated pollination as a practical breeding technique.

\section{INTRODUCTION}

The use of irradiated pollen to transfer single genes from the pollen parent to the seed parent in crosspollination was first proposed by Pandey (1975). Subsequently, it was observed that when pollen was irradiated, the pollen nuclei were "pulverized" and the resultant nuclear "debris" was discharged onto the embryo sac and fused with the egg cells Grant et al., 1980). On the basis of these observations, Pandey $(1980 a, b)$ further proposed that the method of pollinating plants with irradiated pollen could be used for "egg transformation", defined is the transfer of limited intact genes rather than the total pollen genome to the egg cell. He suggested that transformation could be the result of diploid parthenogenesis of the egg induced by irradiated pollen, followed by the incorporation of paternal chromatin during embryogenesis. In the companion paper, we reported the use of irradiated pollen of the rice cultivar Basmati, having dominant genetic markers, to pollinate the maternal cultivar Bellemont, having recessive markers Chin and Gordon, 1989). In the first generation,

Present address: CSIRO, Division of Plant Industry, GPO Box 1600, Canberra, ACT 2601, Australia. all the M1 progeny were either normal hybrid plants indistinguishable from the $\mathrm{F} 1$ controls, or were hemizygous recessive plants in which certain dominant paternal alleles were lost. This reduction in the transmission of paternal alleles was accompanied by morphological mutations and sterility. In total, 17,626 rice florets were pollinated with irradiated pollen but not a single M1 plant was found to contain only one or a few paternal traits of the pollen parent in a largely maternal genetic background. Therefore, "egg transformation" by irradiated pollen was not shown to have occurred in the rice plants.

It has been suggested that pollination with irradiated pollen may nevertheless be useful in practical plant breeding by causing a shift in the segregation ratio towards the maternal phenotypes in the second (M2) generation. This effect was observed in barley, (Powell et al., 1983) and wheat, (Snape et al., 1983). Compared to backcrossing, this could be a quicker method to produce pure breeding maternal progeny with a few specific paternal characteristics. This issue of "maternal shift" will be addressed in this report of the genetic consequences of pollination with irradiated pollen in the M2 generation of rice plants. 
MATERIALS AND METHODS

\section{M2 and M3 plants}

Over two seasons, a total of $66 \mathrm{M} 2$ families (857) plants) were field-planted. These M2 families were obtained from selfing the randomly selected M1 plants which were derived from crosses with pollen given various radiation doses. M2 families were planted in randomized single rows consisting of 15 to 20 plants per row. As controls, a total of 15 F2 families (212 plants) were also grown. M2 and F2 plants were assessed for final plant height, total tiller number, number of days to anthesis, leaf texture, anthocyanin pigmentation on seed apiculus, seed awning and seed phenol staining reaction. All assessments were done as reported in the previous paper of this series. One M2 family with apparent paternal shift was grown on to M3 generation. All the $15 \mathrm{M} 2$ plants of this family were selfed to produce M3 lines and 20 plants of each of the $15 \mathrm{M} 3$ lines were field-grown and scored for leaf texture. These $15 \mathrm{M} 2$ plants were also examined for meiosis. For meiotic studies, panicles were collected when the auricle of the flag leaf had reached the same height as the auricle of the preceding leaf (after De Datta, 1981); Coffman and Herrera, 1980). Florets with immature pollen were fixed with Carnoy's fixative (six parts ethanol, three parts chloroform, one part acetic acid) at least overnight at $4^{\circ} \mathrm{C}$. Hydrolysis and Feulge staining was done as for mitotic studies.

\section{Data analysis}

Duncan's multiple comparisons were done on th. statistical software SAS (Statistical Analysis Sys tem, 1982 edition) using the general linear mode procedure (PROC GLM). Skewness and kurtosi tests on frequency distributions was done usin: the frequency procedure (PROC FREQ) on th SAS. Chi-square and t-tests were calculated on : program written in FORTRAN. Cluster analysi was carried out on the computer progran "HACLUS" written by Mr I. H. De Lacy of th' Department of Agriculture, University of Queens land, St. Lucia, Australia.

\section{RESULTS}

\section{Quantitative traits}

The means and standard error of means of plan height, tiller number and number of days tc anthesis obtained from two seasons of field plant ing are shown in table 1. Results of Duncan: multiple range tests on the means are also shown Phenotypic frequency distributions of these thre phenotypic traits are shown in fig. 1(a) and 1(b)

Table 1 Means and standard error of means of three quantitative traits of F2 and M2 progenies from two seasons of field trial

\begin{tabular}{|c|c|c|c|c|c|c|c|c|}
\hline \multirow[b]{2}{*}{ Treatment } & \multirow{2}{*}{$\begin{array}{l}\text { No. of } \\
\text { family }\end{array}$} & \multirow{2}{*}{$\begin{array}{l}\text { No. of } \\
\text { plant }\end{array}$} & \multicolumn{2}{|c|}{ Height $(\mathrm{cm})$} & \multicolumn{2}{|c|}{ Tiller number } & \multicolumn{2}{|c|}{ Anthesis (days) } \\
\hline & & & Mean & S. E. & Mean & S. E. & Mean & S. E. \\
\hline \multicolumn{9}{|l|}{ First season } \\
\hline Bellemont & 4 & 51 & $90 \cdot 9 c$ & 0.74 & $5 \cdot 3 d$ & 0.42 & $119 \cdot 2 d$ & $1 \cdot 13$ \\
\hline Basmati & 4 & 56 & $151 \cdot 7 \mathrm{a}$ & $3 \cdot 00$ & $36 \cdot 4 a$ & 1.94 & $144 \cdot 4 a$ & 0.52 \\
\hline $\mathrm{F} 2$ & 10 & 113 & $135 \cdot 2 b c$ & $2 \cdot 07$ & $22 \cdot 5 b$ & $1 \cdot 10$ & $135 \cdot 9 \mathrm{c}$ & $1 \cdot 06$ \\
\hline $0.5 \mathrm{krad}$ & 10 & 121 & $138 \cdot 3 b$ & $2 \cdot 41$ & $23 \cdot 3 b$ & $1 \cdot 42$ & $135 \cdot 3 c$ & 0.94 \\
\hline $1 \mathrm{krad}$ & 10 & 111 & $134 \cdot 4 \mathrm{bc}$ & 1.93 & $21 \cdot 3 b c$ & $1 \cdot 00$ & $131 \cdot 7 \mathrm{c}$ & 0.95 \\
\hline $2 \mathrm{krad}$ & 8 & 102 & $138 \cdot 1 b$ & $2 \cdot 03$ & $17 \cdot 6 c$ & 0.82 & $134 \cdot 2 \mathrm{c}$ & 0.98 \\
\hline $4 \mathrm{krad}$ & 10 & 121 & $130 \cdot 0 \mathrm{c}$ & $2 \cdot 18$ & $22 \cdot 5 b$ & $1 \cdot 74$ & $133 \cdot 0 \mathrm{c}$ & $1 \cdot 02$ \\
\hline $6 \mathrm{krad}$ & 4 & 37 & $138 \cdot 2 b$ & $3 \cdot 12$ & $23 \cdot 3 b$ & $2 \cdot 40$ & $141 \cdot 0 \mathrm{~b}$ & $1 \cdot 59$ \\
\hline \multicolumn{9}{|c|}{ Second season } \\
\hline Bellemont & 2 & 40 & $96 \cdot 7 \mathrm{c}$ & $1 \cdot 25$ & $3 \cdot 3 c$ & 0.68 & $115 \cdot 0 \mathrm{c}$ & 0.78 \\
\hline Basmati & 2 & 40 & $161 \cdot 1 \mathrm{a}$ & $1 \cdot 17$ & $22 \cdot 2 a$ & $1 \cdot 04$ & $140 \cdot 0 \mathrm{a}$ & 0.89 \\
\hline $\mathrm{F} 2$ & 5 & 99 & $143 \cdot 6 \mathrm{~b}$ & $2 \cdot 13$ & $13 \cdot 7 b$ & 0.62 & $131 \cdot 5 b$ & $1 \cdot 39$ \\
\hline $5 \mathrm{krad}$ & 9 & 179 & $141 \cdot 8 b$ & $1 \cdot 53$ & $11 \cdot 1 b$ & $0 \cdot 36$ & $134 \cdot 1 b$ & 0.85 \\
\hline $6 \mathrm{krad}$ & 3 & 60 & $137 \cdot 6 b$ & $2 \cdot 37$ & $12 \cdot 6 b$ & 0.36 & $137 \cdot 3 b$ & 1.49 \\
\hline $8 \mathrm{krad}$ & 3 & 46 & $141 \cdot 1 b$ & $2 \cdot 70$ & $11 \cdot 6 \mathrm{~b}$ & 0.77 & $133 \cdot 6 b$ & 1.80 \\
\hline $10 \mathrm{krad}$ & 9 & 80 & $144 \cdot 0 \mathrm{~b}$ & $2 \cdot 07$ & $13 \cdot 7 \mathrm{~b}$ & 0.71 & $132 \cdot 6 b$ & 1.49 \\
\hline
\end{tabular}

Means with the same letters are not different at the 5 per cent level of Duncan's multiple range test. 
a

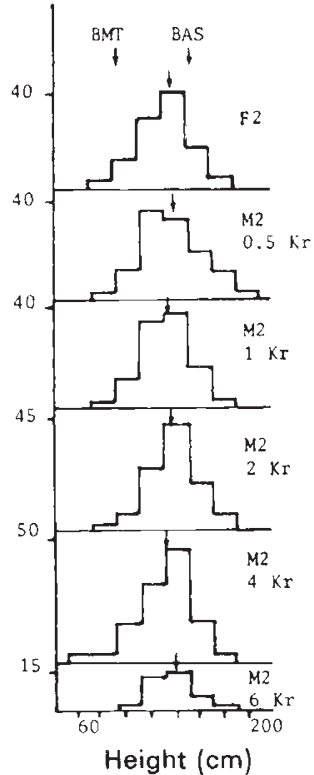

b

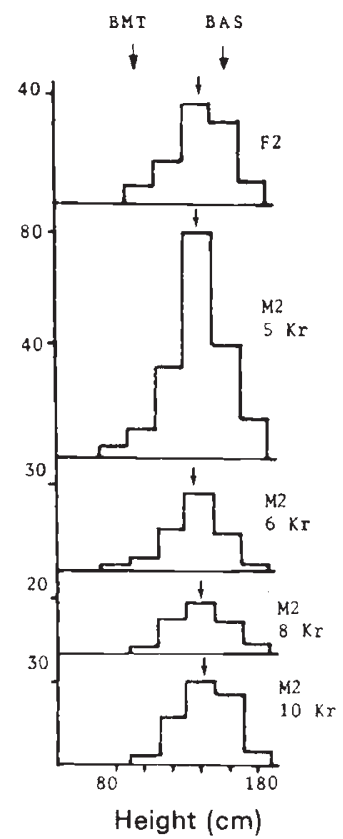

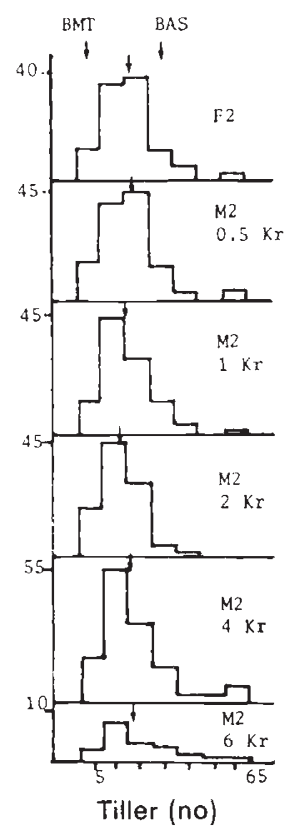

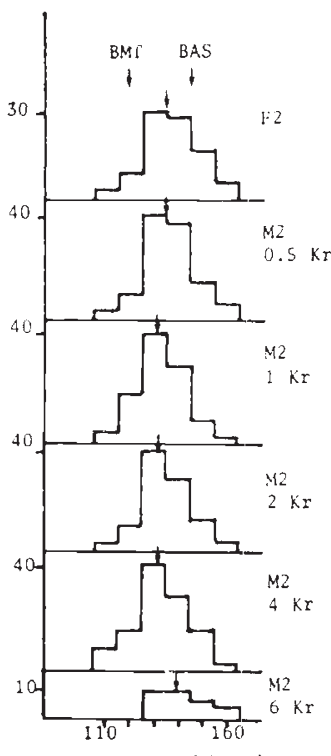

Anthesis (days)

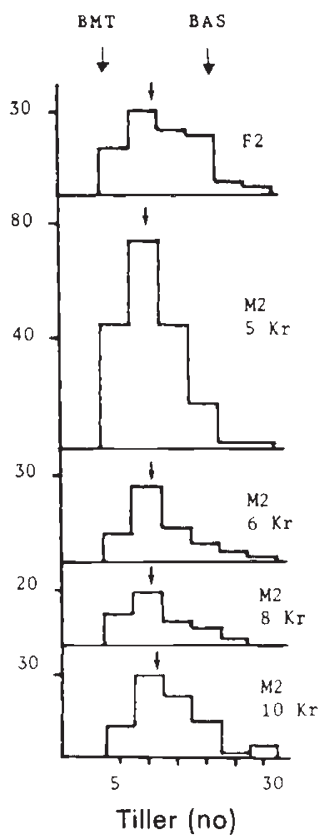

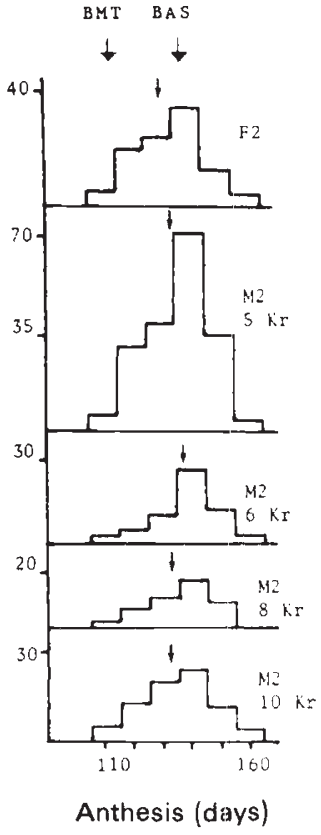

Figure 1 (a) Frequency distributions of three quantitative traits of F2 and M2 progeny from the first season of field trial. All means are indicated by arrows and the number of plants are shown on the vertical axes. Bellemont (BMT) is the female parent and Basmati (BAS) the male parent. (b) Frequency distributions of three quantitative traits of $\mathrm{F} 2$ and $\mathrm{M} 2$ progeny from the second season of field trial. All means are indicated by arrows and the number of plants are shown on the vertical axes. Bellemont (BMT) is the female parent and Basmati (BAS) the male parent.

These distributions are tested for departure from normality by two sample statistics (g1) and (g2) which measure skewness (asymmetry) and kurtosis (peakedness) respectively. Test of significance of g1 and g2 are after Sokal and Rohlf (1981) as follows: $t_{s}=(g 1-P 1) / S_{g 1}$ and $t_{s}=(g 2-P 2) / S_{g 2}$, where $\mathrm{P} 1$ and $\mathrm{P} 2$, the population parameters, are equal to zero for a normally distributed population. 
Table 2 Test of departure from normality on the frequency distributions of F2 and M2 phenotypes. Data were obtained from two seasons of field trial. The two sample statistics (g1) and (g2) test for skewness and kurtosis respectively

\begin{tabular}{|c|c|c|c|c|c|c|c|c|c|c|c|c|}
\hline \multirow[b]{2}{*}{ Treatment } & \multicolumn{4}{|l|}{ Height } & \multicolumn{4}{|l|}{ Tiller } & \multicolumn{4}{|c|}{ Anthesis } \\
\hline & gl & $t$ & $\mathrm{~g} 2$ & $t$ & g1 & $t$ & $\mathrm{~g} 2$ & $t$ & $\mathrm{~g} 1$ & $t$ & $\mathrm{~g} 2$ & $t$ \\
\hline \multicolumn{13}{|c|}{ First season } \\
\hline $\mathrm{F} 2$ & $0 \cdot 3$ & ns & 0.0 & ns & $7 \cdot 1 \mathrm{R}$ & * & $11 \cdot 1 \mathrm{p}$ & * & $-0 \cdot 2$ & ns & $1 \cdot 4$ & $\mathrm{~ns}$ \\
\hline $0.5 \mathrm{krad}$ & 0.6 & ns & $1 \cdot 0$ & ns & $15 \cdot 6 \mathrm{R}$ & $*$ & $39 \cdot 8 p$ & * & 0.6 & ns & $-0 \cdot 1$ & ns \\
\hline $1 \mathrm{krad}$ & $1 \cdot 3$ & ns & 0.6 & ns & $4 \cdot 4 \mathrm{R}$ & $*$ & $4 \cdot 0 p$ & $*$ & $-1 \cdot 1$ & ns & 0.7 & $\mathrm{~ns}$ \\
\hline $2 \mathrm{krad}$ & $0 \cdot 3$ & ns & 0.2 & ns & $3 \cdot 3 \mathrm{R}$ & $*$ & $2 \cdot 6 p$ & * & 0.4 & ns & -0.1 & $\mathrm{~ns}$ \\
\hline $4 \mathrm{krad}$ & $-4 \cdot 0 \mathrm{~L}$ & $*$ & $3 \cdot 9 p$ & $*$ & $18 \cdot 8 \mathrm{R}$ & * & $57 \cdot 4 p$ & * & $-0 \cdot 3$ & ns & $-0 \cdot 2$ & $\mathrm{~ns}$ \\
\hline $6 \mathrm{krad}$ & 0.7 & ns & $0.8^{r}$ & ns & $4 \cdot 2 \mathrm{R}$ & * & $5 \cdot 1 p$ & * & $1 \cdot 0$ & ns & $-1 \cdot 2$ & $\mathrm{~ns}$ \\
\hline
\end{tabular}

Second season

\begin{tabular}{|c|c|c|c|c|c|c|c|c|c|c|c|c|}
\hline F2 & $-2 \cdot 0$ & ns & $1 \cdot 2$ & $\mathrm{~ns}$ & $2 \cdot 6 \mathrm{R}$ & $*$ & $10 \cdot 1 p$ & $*$ & $-1 \cdot 4$ & $\mathrm{~ns}$ & $2 \cdot 0$ & ns \\
\hline $5 \mathrm{krad}$ & -1.9 & ns & $1 \cdot 2$ & $\mathrm{~ns}$ & $6 \cdot 0 \mathrm{R}$ & * & $4.9 p$ & $*$ & -1.2 & $\mathrm{~ns}$ & -0.4 & ns \\
\hline $6 \mathrm{krad}$ & -0.5 & ns & 0.9 & $\mathrm{~ns}$ & $4 \cdot 7 \mathrm{R}$ & $*$ & $5 \cdot 3 p$ & $*$ & $-1 \cdot 0$ & $\mathrm{~ns}$ & $-0 \cdot 2$ & ns \\
\hline $8 \mathrm{krad}$ & 0.3 & $\mathrm{~ns}$ & $-1 \cdot 3$ & ns & $2 \cdot 3 \mathrm{R}$ & $*$ & $2 \cdot 2 \mathrm{p}$ & $*$ & $-1 \cdot 3$ & $\mathrm{~ns}$ & 0.5 & $\mathrm{~ns}$ \\
\hline $10 \mathrm{krad}$ & -0.1 & $\mathrm{~ns}$ & -0.7 & ns & $3 \cdot 8 \mathrm{R}$ & $*$ & $2 \cdot 4 p$ & $*$ & $-1 \cdot 2$ & $\mathrm{~ns}$ & $-0 \cdot 1$ & ns \\
\hline
\end{tabular}

A negative significant $\mathrm{gl}$ indicates left-skew (L) and a positive significant $\mathrm{g} 1$ indicates right-skew (R). A negative significant $\mathrm{g} 2$ indicates platykurtosis (having fewer items at the mean and at the tails than the normal curve) and a positive significant g2 indicates leptokurtosis (p), i.e., having more items near the mean and at the two tails). Student's $t$-test ( $t)$ of g1 and g2 are either non-significant (ns) or significant at the 5 per cent level $\left(^{*}\right)$.

$\mathrm{S}_{\mathrm{g} 1}$ and $\mathrm{S}_{\mathrm{g} 2}$ are approximated by $6 / n$ and $24 / n$ respectively where $n$ is the number of plants sampled in each dosage treatment. The null hypotheses being tested are: $\mathrm{H}_{0}: \mathrm{P} 1=0$, and $\mathrm{H}_{0}: \mathrm{P} 2=0$. Results of these normality tests are shown in table 2 .

Examination of tables 1 and 2 shows that in plant height, all M2 means are not significantly different from the F2 means, except for the mean height of the $4 \mathrm{krad}$ treatment. Again with the exception of $4 \mathrm{krad}$, the phenotypic frequencies of all the M2 populations are normally distributed like that of the F2. In the $4 \mathrm{krad}$ treatment, two extremely dwarf plants were found $(42 \mathrm{~cm}$ and $45 \mathrm{~cm})$. These plants were responsible for the reduction of the overall mean height in the $4 \mathrm{krad}$ treatment and they have caused the frequency distribution of this treament to be left-skewed and leptokurtic, i.e., having more items near the mean and at the two tails (fig. 1(a)). These dwarf plants can be interpreted as having descended from M1 parents which were harbouring damaged allele(s) from the irradiated pollen and dwarfness is revealed only when the damaged allele(s) are in homozygous condition in the M2 generation.

In both tiller number and the number of days to anthesis, all M2 means are the same as F2 means in general, except that the $2 \mathrm{krad}$ treatment has less tillers than the F2's and that $6 \mathrm{krad}$ from the first season of field trial had taken more days to flower than the F2's (table 1). If these results were taken to mean a loss in plant vigour, the effect would only have been a very mild one as these treatment means differ only very slightly from the other M2 means. In terms of frequency distributions, all M2 treatments are right-skewed and leptokurtic like the F2's in tiller number and all M2 and F2 treatments are normally distributed in anthesis (table 2).

\section{Qualitative traits}

M2 families from $0 \cdot 5-10 \mathrm{krad}$ dosage treatments were examined for the major gene markers: leaf texture (TXT), anthocyanin (ANC), awning $(\mathrm{AWN})$, and phenol staining (PHE). For each marker, the segregation data of the individual radiation dosages is first considered. As every dosage treatment is composed of several M2 families which have to be statistically homogeneous before their segregation data may be pooled, standard heterogeneity chi-square test was first carried out. Results showed that each of the dosage treatments contained homogeneous M2 families and the segregation data of the respective treatments may therefore be combined. Chi-square tests of the segregation ratios of the four markers taken individually or taken all together are shown in table 3. All segregations are in the expected ratios 
Table 3 Chi-square tests on M2 segregation ratios of the four genetic markers: leaf texture (TXT), anthocyanin (ANC), awning (AWN) and phenol reaction (PHE). The markers are tested individually or jointly. Chi-squares are significant at the 1 per cent level $\left({ }^{* *}\right)$ or the 5 per cent level $(*)$

\begin{tabular}{|c|c|c|c|c|c|c|c|c|c|}
\hline & \multicolumn{7}{|c|}{ Single locus segregations } & \multirow[b]{2}{*}{$8 \mathrm{Kr}$} & \multirow[b]{2}{*}{$10 \mathrm{~K}_{\mathrm{r}}$} \\
\hline & $\mathrm{F} 2$ & $0.5 \mathrm{Kr}$ & $1 \mathrm{Kr}$ & $2 \mathrm{Kr}$ & $4 \mathrm{Kr}$ & $5 \mathrm{Kr}$ & $6 \mathrm{Kr}$ & & \\
\hline TXT & $1 \cdot 82$ & $3 \cdot 37$ & $0 \cdot 24$ & 0.05 & 0.62 & 3.05 & $10 \cdot 40^{* *}$ & 0.00 & $1 \cdot 35$ \\
\hline ANC & 0.43 & 1.92 & $0 \cdot 32$ & $1 \cdot 38$ & $4 \cdot 49^{*}$ & 0.53 & 0.05 & $0 \cdot 17$ & 0.01 \\
\hline AWN & 0.05 & $1 \cdot 86$ & $6 \cdot 25^{*}$ & $0 \cdot 18$ & 0.99 & 0.00 & $3 \cdot 35$ & $0 \cdot 03$ & $1 \cdot 03$ \\
\hline \multirow[t]{4}{*}{ PHE } & $2 \cdot 77$ & $1 \cdot 34$ & $0 \cdot 15$ & $0 \cdot 00$ & $0 \cdot 07$ & $0 \cdot 00$ & $0 \cdot 03$ & $1 \cdot 86$ & $0 \cdot 02$ \\
\hline & \multicolumn{7}{|c|}{ Joint segregation of TXT/AWN/PHE/ANC } & & \\
\hline & $\mathrm{F} 2$ & $0.5 \mathrm{Kr}$ & $1 \mathrm{Kr}$ & $2 \mathrm{Kr}$ & $4 \mathrm{Kr}$ & $5 \mathrm{Kr}$ & $6 \mathrm{Kr}$ & $8 \mathrm{Kr}$ & $10 \mathrm{Kr}$ \\
\hline & $24 \cdot 73$ & $23 \cdot 55$ & $16 \cdot 04$ & $16 \cdot 22$ & $10 \cdot 71$ & $13 \cdot 47$ & $21 \cdot 12$ & $13 \cdot 57$ & $9 \cdot 98$ \\
\hline
\end{tabular}

except in three instances, i.e., $1 \mathrm{krad}(\mathrm{AWN}$ ), $4 \mathrm{krad}$ (ANC) and $6 \mathrm{krad}$ (TXT).

The M2 families responsible for these deviations are revealed in table 4 , when the $58 \mathrm{M} 2$ families were examined individually for their segregations at the four markers. These M2 families are: $119-1$ (1 krad), I33-1 (4 krad) and I84-2 $(6 \mathrm{krad})$. Table 4 also shows two other M2 families that had deviated from expected segregations: I5-4 $(0.5 \mathrm{krad}, \mathrm{AWN})$ and $141-2(2 \mathrm{krad}$, TXT) but the overall segregations are normal for the marker AWN in $0.5 \mathrm{krad}$ and for the marker TXT in $2 \mathrm{krad}$. Table 4 shows that each dosage treatment only contains one aberrantly segregating M2 family. There is no evidence that such families had occurred more frequently with increasing dosages. In addition, each aberrantly segregating M2 family is only affected at one of the four markers. There are four cases where the excess phenotype is dominant (paternal) and two cases where it is recessive (maternal). Therefore, radiation effects on the segregations of the major gene traits appear to be mild and random in the rice plants.
The frequency with which a maternal allele is transmitted from the M1 to the M2 generation can also be calculated from the M2 segregation data. For the two monogenic traits of leaf texture (TXT) and seed phenol reaction (PHE), this frequency $(q)$ is the square-root of the proportion of recessive phenotypes in a segregation. The means and standard errors (S.E.) of $q$ 's for TXT and PHE are shown in table 5. Student's $t$-tests of the difference between the estimated $q$ values and the expected values of 0.5 were calculated by: $r=(q-0.5) /$ S.E., with $2 n-2$ degree of freedom ( $n$ is sample size). Table 5 shows that the transmission frequency of maternal alleles in TXT and PHE are normal in all but one M2 family. The only exception being I84-2, descended from 6 krad dosage treatment. In this case, only about 24 per cent of the maternal allele for the leaf texture marker had been transmitted.

To further investigate the effects of this apparent paternal shift, all the members of this M2 family (I84-2) were examined for meiosis. Normal meiotic processes were observed. These M2

Table 4 M2 families which have deviated from the expected segregation ratios at the 5 per cent significance level

\begin{tabular}{|c|c|c|c|c|c|}
\hline \multirow[b]{2}{*}{ Treatment } & \multirow[b]{2}{*}{$\begin{array}{l}\text { No, of } \\
\text { family }\end{array}$} & \multicolumn{4}{|c|}{ Affected M2 families } \\
\hline & & No. & Identity & $\begin{array}{l}\text { Marker } \\
\text { affected }\end{array}$ & $\begin{array}{l}\text { Excess } \\
\text { phenotypes }\end{array}$ \\
\hline $\mathrm{F} 2$ & 15 & 0 & - & - & - \\
\hline $0.5 \mathrm{krad}$ & 10 & 1 & I5-4 & AWN & dominant \\
\hline $1 \mathrm{krad}$ & 9 & 1 & I $19-1$ & AWN & dominant \\
\hline $2 \mathrm{krad}$ & 8 & 1 & I $41-2$ & TXT & recessive \\
\hline $4 \mathrm{krad}$ & 10 & 1 & $133-1$ & ANC & dominant \\
\hline $5 \mathrm{krad}$ & 9 & 0 & - & - & - \\
\hline $6 \mathrm{krad}$ & 4 & 1 & I $84-2$ & TXT & dominant \\
\hline $8 \mathrm{krad}$ & 3 & 0 & - & - & - \\
\hline $10 \mathrm{krad}$ & 5 & 1 & I172-1 & EST & recessive \\
\hline
\end{tabular}

The affected markers are: leaf texture (TXT), awning (AWN), anthocyanin (ANC), and esterase isozyme (EST). 
Table 5 Means and standard error of means of the transmission frequency of maternal allele from $\mathrm{M} 1$ to $\mathrm{M} 2(q)$. Expected $q=0.5$ for normal segregations

\begin{tabular}{lclllll}
\hline $\begin{array}{l}\text { Dosage } \\
\text { (krad) }\end{array}$ & $\begin{array}{l}\text { No. of M2 } \\
\text { family }\end{array}$ & Mean & S. E. & & Mean & S. E. \\
\hline F2 & 15 & 0.4357 & 0.0304 & & 0.5257 & 0.0408 \\
0.5 & 10 & 0.4035 & 0.0632 & & 0.5096 & 0.0430 \\
1 & 9 & 0.4660 & 0.0381 & & 0.5201 & 0.0130 \\
2 & 8 & 0.4578 & 0.0478 & & 0.4891 & 0.0345 \\
4 & 10 & 0.4576 & 0.0445 & & 0.4956 & 0.0382 \\
5 & 9 & 0.4191 & 0.0407 & 0.4812 & 0.0423 \\
6 & 4 & $0.2406^{*}$ & 0.0968 & 0.4676 & 0.0399 \\
8 & 3 & 0.5122 & 0.0576 & 0.3886 & 0.0766 \\
10 & 5 & 0.4418 & 0.0322 & 0.4599 & 0.0829 \\
\hline
\end{tabular}

*Significant $t$-test at the 5 per cent level.

plants were also selfed to produce M3 progeny which were assessed for leaf texture. M3 lines were either non-segregating or segregating in the expected $3: 1$ ratio. The ratio between non-segregating M3 lines (descended from homozygous dominant or homozygous recessive M2 parents) and segregating M3 lines (descended from heterozygous M2 parents) was 6:9. The expected ratio is $5: 10$. Chi-square test for goodness-of-fit $(0 \cdot 07)$ is not significant at the 5 per cent level. Pandey (1975) had suggested in his original model that paternal shift in M2 segregations could be explained by assuming the M1 parent as being "triallelic" for a given marker, harbouring an additional allele from the irradiated pollen. In the present studies however, normal M2 meiosis and M3 segregations tend to rule out the likelihood of the presence of extra paternal genetic materials (as chromosome segments or chromatin fragments) in the genome of the M1 parent from which the M2 family I84-2 had descended.

In three polygenic traits, M2 means are the same as that of the F2 control, with only slight reduction in plant height in one dosage treatment and in tiller number in another treatment. The former variation was due to the presence of two unusual dwarf plants which themselves reflected the inheritance of mutational damage in the $\mathrm{M} 1$ parents after pollination with irradiated pollen, instead of the transfer of single genes from the irradiated pollen to these M1 parents. In both cases, the altered means are still considerably higher than the maternal means and a maternal shift is not observed. Pollination with irradiated pollen also did not alter the distributions of the phenotypic frequencies of the M2 populations compared to that of the F2 populations.

In five major gene markers, all but six of the 244 segregations examined are in the expected ratios. Variations are seen in both directions, segregating for excess paternal as well as maternal phenotypes and there is no consistent trend in favour of a "maternal shift". A paternal shift, such as those observed in the segregations of $1 \mathrm{krad}$ (awning), 4 krad (anthocyanin) and $6 \mathrm{krad}$ (leaf texture), was also reported by Daskalov (1984) and Davies (1984) without explanation. It is unlikely that this increase in the paternal allelic frequency illustrates the presence of additional paternal genetic materials transferred from irradiated pollen. This is because normal meiosis in the $6 \mathrm{krad}$ M2 plants that had segregated for excess paternal phenotype in leaf texture, and normal segregations of the M3 progeny from these M2 parents were observed. Overall, irradiated pollination in rice has only shown very mild genetic effects in the M2 populations.

\section{DISCUSSION}

\section{The "gene transfer" hypothesis}

The hypothesis of limited gene transfer mediated by pollination with irradiated pollen has not been shown in the present investigation in the rice plants. This hypothesis is by now largely repudiated by other studies (Chyi and Sanford, 1985; Powell and Caligari, 1985; Raquin, 1985) and the present findings in rice are consistent with the conclusions of these reports. Instead of gene transfer, the probable mechanism of the rare effects of pollen irradiation in rice is induced mutations to the paternal alleles in the pollen genome which are then inherited by the M1 progeny after pollination, resulting in the production of hemizygous recessive, mutated and sometimes also sterile M1 plants. 


\section{Comparison with other studies}

The overall effect of pollination with irradiated pollen in rice is that on the one hand, affected M1 plants are all sterile, and on the other hand, all the fertile M1 plants are unaffected, showing normal inheritance in the next two generations. These consequences are very similar to the effects of irradiated pollination in tomato (Zamir, 1983); are comparable to the effects on maize (Pandey, 1983) and tobacco (Engvild, 1985); and are very different to the effects on wheat (Snape et al., 1983) and barley (Powell et al., 1983). Unless otherwise stated, these references are used in the following discussions. It should also be noted that embryo rescue was performed in the barley experiments.

Firstly, seed set is inhibited by $20 \mathrm{krad}$ in rice (this study), tomato and tobacco; by $10 \mathrm{krad}$ in maize, $5 \mathrm{krad}$ in wheat and $2 \mathrm{krad}$ in barley. $\mathrm{LD}_{50}$ is $10 \mathrm{krad}$ in rice (this study), $6 \mathrm{krad}$ in tomato, $5 \mathrm{krad}$ in maize and $12 \mathrm{krad}$ in tobacco. Whereas in wheat, $L D_{50}$ is $1.5 \mathrm{krad}$. Secondly, in wheat and tobacco (Werner et al., 1984), aneuploidy was observed in over 50 per cent of the M1 plants but only a quarter of M1 maize plants were aneuploid. In barley, aneuploidy was absent in the M1 generation and was rare in the M2 ( $<2$ per cent). In rice, chromosomal aberrations were not observed (this study). Thirdly, radiation induced mutational loss of dominant paternal markers was most common in wheat, occurring in 35 per cent of the M1 plants at two markers. This effect was moderate in tobacco (21 per cent, Werner and Cornish 1985), in maize ( 23 per cent) and barley ( 25 per cent) but very mild in tomato ( 1 per cent) and in rice ( 5 per cent). Finally, a maternal shift in the M2 segregations, indicating reduced transmission of paternal alleles from M1 to M2, was observed in wheat, tobacco and barley but not in rice and tomato. These comparisons show that substantial differences in the consequences of pollen irradiation do exist among different plant species.
Chromosome number, chromosome size, ploidy level and nuclear DNA content are some of the important biological parameters in determining the radio-sensitivity of a species. Given the same radiation dosage, a species with more and/or bigger chromosomes, containing a higher DNA content, provides a larger number of target sites and is thus more likely to sustain a radiation hit (Lawrence, 1971). Thus, the radio-resistant species are those with fewer and smaller chromosomes of low DNA content. The different responses to irradiated pollination of the six species discussed above may be explained in terms of their radiosensitivity, measured by the four biological attributes just mentioned. This is achieved by carrying out a cluster analysis on the four-attribute by six-species matrix presented in table 6 . The objective is to classify the six plant species in terms of the four selected biological attributes, so as to explain the difference in response they have shown to pollination with irradiated pollen.

Cluster analysis was carried out using the hierarchical agglomerative procedure whereby classification proceeds by progressive fusion beginning with the individual species and ending with the complete population. This method is based on a measure of dissimilarity applied over all the selected attributes (Williams, 1976). The dissimilarity measured $\left(D^{2}\right)$ ranges from zero for complete similarity to infinity for complete dissimilarity (Clifford and Stephenson, 1975). For the four-by-six matrix, $\left(D^{2}\right)$ between any two species ( $i$ th and $j$ th) is calculated by:

$$
\left(D_{i j}\right)^{2}=\sum_{k=1}^{4}\left(X_{i k}-X_{j k}\right)^{2}
$$

which is the sum of squares of the difference between two species over all the attributes $(k$ 's). The greater the difference between two species at each attribute, the greater the distance. Before calculating the $D^{2}$, the raw data in table 6 are standardized. Standardization reduces all attribute

Table 6 A 4-attribute by 6-species matrix for cluster analysis to establish the proximity relationships of six plant species

\begin{tabular}{lcccccc}
\hline & Wheat & Barley & Maize & Tobacco & Tomato & Rice \\
\hline $2 n=$ & 42 & 14 & 20 & 48 & 24 & 24 \\
Chromosome size $(\mu \mathrm{m})$ & $8-14^{1}$ & $7-8^{2}$ & $4-5^{3}$ & $3-4^{4}$ & $2-3^{5}$ & $1-2^{6}$ \\
Ploidy level & 6 & 2 & 2 & 4 & 2 & 2 \\
Haploid $^{7}$ DNA $(\mathrm{pg})$ & $17 \cdot 3$ & $5 \cdot 5$ & 5 & 4 & 1 & 0.6
\end{tabular}

\footnotetext{
${ }^{1}$ Endo and Gill (1984); ${ }^{2}$ Islam (1980); ${ }^{3}$ Filion and Walden (1973); ${ }^{4}$ Goodspeed (1954); ${ }^{5}$ Rick and Butler (1956); ${ }^{6}$ Kurata et al. (1978); ${ }^{7}$ Bennett and Smith (1976).
} 


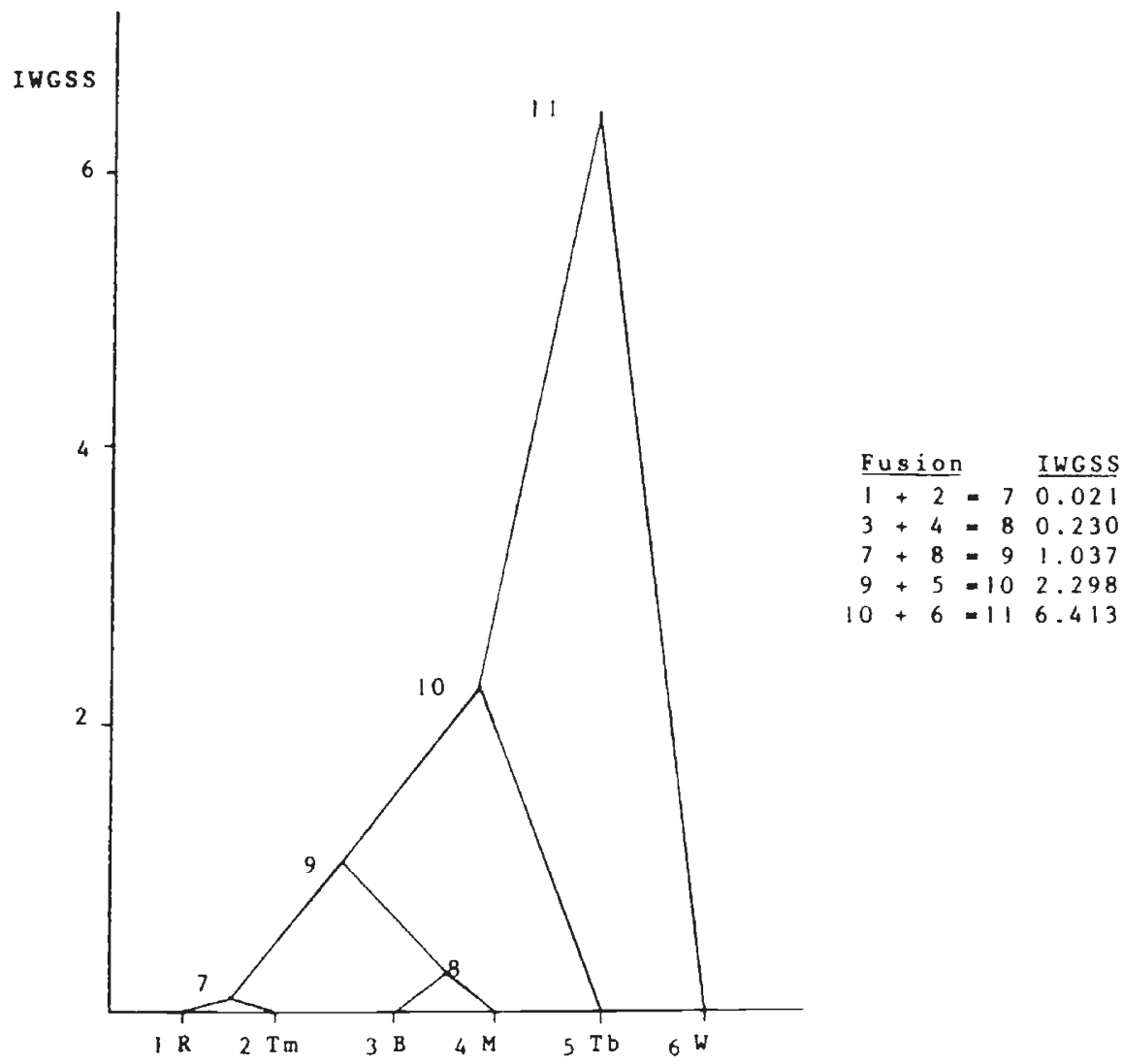

Figure 2 Dendogram for the cluster analysis of rice (R), tomato (Tm), barley (B), maize (M), tobacco (Tb) and wheat (W), based on chromosome number, chromosome size, ploidy level and haploid nuclear DNA content. The analysis was done on the computer program "HACLUS", using the classification strategy of incremental sum of squares which minimizes the increase in the within group sum of squares, or IWGSS, after fusions.

means to zero and attribute variance to unity so that the contribution of each attribute is measured in terms of their variations instead of their absolute values (Sneath and Sokal, 1973). Standardization, squared Euclidean distance, dissimilarity matrix and other calculations were all performed on the computer program "HACLUS" (see method). The classification strategy used was one known as "the incremental sum of squares" (ISS) in which the distance between two groups is defined as the increase in the sum of squares of deviation from the group mean after fusion as compared with the sum of the two within group sum of squares before fusion (Williams, 1976). In other words, the ISS strategy seeks the fusion which minimizes the increase in the within group sum of squares (IWGSS), (De Lacy, 1981). Results of the cluster analysis are shown in fig. 2 . The six species appear along the $\mathrm{X}$-axis and IWGSS appears on the $\mathrm{Y}$ axis. The level of fusion progresses with increasing
IWGSS. It can be seen that on the basis of the four given attributes, the species rice is very similar to tomato forming one group and barley is similar to maize forming another group. These two groups have more similarity between them than with the rest and are fused into one cluster. Of the two remaining species, tobacco is more similar to this cluster than is wheat which is most unlike all the other species.

These proximity relationships among the six species correspond very well with the pollen irradiation responses of the respective species. At the one end of the scale is rice which has a high $\mathrm{LD}_{50}$ for seed set $(10 \mathrm{krad})$ and at the other end the most sensitive species, wheat, with an $\mathrm{LD}_{50}$ of $1.5 \mathrm{krad}$. No cytogenetic abnormalities and fewer hemizygous plants were observed in rice and tomato whereas they were more frequent in wheat and tobacco. Therefore, the relative lack of heritable variations observed in the present studies in rice 
could be explained in part by the greater radioresistance of the pollen genome and in part by the fact that induced genetic damages, when they occur, are most likely to be lethal due to the haploidy of the rice pollen.

\section{Implications of the present study}

In terms of rice breeding, the method of pollination with irradiated pollen has not been promising: no transfer of limited genes in inter-varietal crosses has been shown; no haploid plants have been produced; and there has been no preferential production of pure breeding maternal materials which may have a few specific paternal characteristics. Finally, the fact that irradiated pollen has produced very little heritable variations also suggests that the technique may not even be useful in mutation breeding.

Acknowledgements S.-F. Chin wishes to thank Dr Gordon, Dr Byth and Professor Britten of the University of Queensland for their supervision of this PhD work, which was supported by a University of Queensland Postgraduate Research Scholarship. We also thank Dr Larkin of CSIRO, Plant Industry, for reviewing this manuscript.

\section{REFERENCES}

BENNETT, M. D. AND SMITH, J. B. 1976. Nuclear DNA amounts in angiosperms. Phil. Trans. Roy. Soc. London B, 274, 227-274.

CHIN, S.-F. AND GORDON, G. H. 1989. Pollination with irradiated pollen in rice-Oryza sativa L. I. The first (MI) generation. Heredity 63, 163-170.

CHYI, Y. S. AND SANFORD, J. C. 1985. "Egg transformation" induced by irradiated pollen in Nicotiana: a reexamination. Theor. Appl. Genet., 70, 433-439.

CLIFFORD, H. T. AND STEPHENSON, W. 1975. An Introduction to Numerical Classification. Academic Press, New York, San Francisco, London.

COFFMAN, W. R. AND HERRERA, R. M. 1980. Rice. In Fehr, W. R. and Hadley, H. H. (eds) Hybridization of Crop Plants, Am. Soc. Agron, pp. 511-522.

DE DATTA, S. K. 1981. Principles and Practices of Rice Production. Wiley, New York.

DE LACY, 1. H. 1981. Cluster analysis of genotype by environment interaction. In Byth, D. E. and Mungomery, V. E. (eds) Interpretation of Plant Response and Adaptation to Agricultural Environments. Aust. Inst. of Ag. Sc., pp. $277-$ 291.

DASKALOV, S. 1984. Pollen irradiation and gene transfer in Capsicum. Theor. Appl. Genet., 68, 135-138.

DAVIES, D. R. 1984. Pollen irradiation and the transfer of maternal genes in Pisum sativum. Theor. Appl. Genet., 67, 245248.
ENGVILD, K. C. 1985. Pollen irradiation and possible gene transfer in Nicotiana species. Theor. Appl. Genet., 69, $457-$ 461 .

ENDO, T. AND MORISHIMA, H. 1983. Rice. In Tanksley, S. D. and Orton, T. S. (eds) Isozymes in Plant Genetics and Breeding-Part B. Elsevier, Amsterdam, pp. 129-146.

FILION, W. G. AND WALDEN, D. B. 1973. Karyotype analysis: The detection of chromosomal alterations in the somatic karyotype of Zea mays L. Chromosoma, 4I, 183-194.

GOODSPEED, T. H. 1954. The Genus Nicotiana. Chronica Botanica Company, Waltham, Massachusetts.

GRANT, J. E., PANDEY, K. K. AND WILliams, E. G. 1980. Pollen nuclei after ionising irradiation for egg transformation in Nicotiana. NZ. J. Bot., 18, 339-341.

ISLAM, A. K. M. R. 1980. Identification of wheat-barley additional lines with N-banding of chromosome. Chromosoma, $76,365-373$

KURATA, N, AND OMURA, T. 1978. Karyotype analysis in rice. I. A new method for identifying all chromosome pairs. Jpn. J. Gen., 53, 251-222.

LAWRENCE, C. W. 1971. Cellular Radiobiology. Edward Arnold, London.

PANDEY, K. K. 1975. Sexual transfer of specific genes without gametic fusion. Nature, 256, 310-313.

PANDEY, K. K. 1980a. Further evidence for egg transformation in Nicotiana. Heredity, 45. 15-29.

PANDEY, K. K. $1980 b$. Parthenogenetic diploidy and egg transformation induced by irradiated pollen in Nicotiana. $N Z$. J. Bot., 18, 203-207.

PANDEY, K. K. 1983. Evidence for gene transfer by the use of sublethally irradiated pollen in Zea mays and theory of occurrence by chromosome repair through somatic recombination and gene conversion. Mol. Gen. Genet., 191, 358-365.

POWELl, W., CALIGARI, P. D. S. AND HAYTER, A. M. 1983. The use of pollen irradiation in barley breeding. Theor. Appl. Genet., 65, 73-76.

POWELL, W. AND CALIGARI, P. D. S. 1985. Irradiated pollen selfs in cultivars of Hordeum vulgare. Heredity, 54 285-287.

RAQUIN, C. 1985. Induction of haploid plants by in-vitro culture of Petunia ovaries pollinated with irradiated pollen. $Z$ Pflanzenzuchtg., 94, 166-169.

RICK, C. AND BUTLER, L. 1956. Cytogenetics of the tomato. Adv. Gen., 8, 267-382.

SNAPE, J. W., PARKER, B. B., SIMPSON, E., A.INSWORTH, C. C., PYNE, P. I. AND LAW, C. N. 1983. The use of irradiated pollen for differential gene transfer in wheat Triticum aestivum. Theor. Appl. Genet., 65, 103-111.

SNEATH, P. H. A. AND SOKAL, R. R. 1973. Numerical Taxonomy-The Principles and Practice of Numerical Classification. W. H. Freeman and Company, San Francisco.

SOKAL, R. R. AND ROHLF, F. J. 1981. Biometry, 2nd edn. Freeman, New York.

WERNER, C. P. AND CORNISH, M. A. 1985. Gene transfer in Nicotiana rustica by means of irradiated pollen. IV. Qualitative characters. Heredity, 55, 315-320.

WERNER, C. P. DUNKIN, I. M., CORNISH, M. A. AND JONES, G. H. 1984. Gene transfer in Nicotiana rustica by means of irradiated pollen. II. Cytogenetical consequences. Hered ity, 52, 113-119.

williams, w. T. 1976. Pattern Analysis in Agricultural Science. CSIRO, Melbourne and Elsevier Scientific Publishing Company.

ZAMIR, D. 1983. Pollen irradiation in tomato: minor effects on enzymic gene transfer. Theor. Appl. Genet., 66, 147-151. 